\title{
COMUNICAÇÃO SOCIAL EM SAÚDE E EDUCAÇÃO: RELATO DE EXPERIÈNCIA
}

\author{
COMMUNICATION SOCIALE EM SANTÉ \\ ET ÉDUCATION: RAPPORT \\ D'UNE EXPÉRIENCE
}

Everardo de Carvalho ${ }^{1}$

CARVALHO, E. Comunicação Social em Saúde e Educação - Relato de Experiência. Rev. Bras. Cresc. Des. Hum. 111 (1): São Paulo, 1993

\section{RESUMO}

O presente trabalho apresenta um relato de experiência realizado pela CNBB - Pastoral da Criança, que optou por desenvolver um modelo de intervenção nos meios de comunicação social no Brasil.

A opção pelo rádio se deu por vários motivos: grande penetração nas populações de baixa renda grande credibilidade, baixos custos, etc.

A decisão de atuar na área de comunicação tem por base o processo de formação da cidadania e o estabelecimento da dimenssão macro e micro-social onde ocorrem e se estabelecem as relações humanas Outro aspecto também importante é o descaso que existe na média brasileira quanto à importância do tema saúde e desenvolv ne nto infantil.

Nesse sentido, optou-se pela elaboração e disseminaçao do ‘ Prol grama Viva a Vida” que entra em 1993, em fase de avaliação.

\section{RESUMÉ}

I1 est présent un rapport d'expériences fait par la $\left(\mathrm{CNBB}^{1}\right)$ - Pastoral da Criança ${ }^{2}$, qui a choisi de développer ub modèle d'intérvention dans les milieux de communication sociale au Brésil

Le choix de la radio à été motive par plusieurs raisons: grande porteé dans les populations à bas revenus, grande credibilité, coüt réduit, etc.

La décision d'agir dans les milieux de communication s'appui dans le processus de formatation de la citoyenneté et dans l'établissement de la dimension macro et micro-sociale où se tissent les relations humaines. Un autre aspect fondamenl;al, est le manque d'intêret de la part des médias brésiliens quant à l'importance de sujets tels que la santé ou le développement infantil. C'est dans ce sens qu'à été prise l'option d'élaborer et diffuser le "Programa Viva a Vida “ qui entre en 1993 dans sa phase d’évaluaton.

1 Médico sanitarista da FNS/MS; assistente técnico em Comunicação Social CNBB - Pastoral da Criança - Brasil. 
A CNBB - Pastoral da Criança fez, há mais de um ano, a opção de criar um modelo de intervenção nos meios de comunicação social no Brasil. Esse modelo foi amadurecido através de sucessivas oficinas de trabalho, por todo o pais, reunindo representantes de vários segmentos sociais e profissionais que lidam com comunicação popular, até que chegássemos a um desenho viável e exequível.

A decisão de atuar na área da comunica,cão de massa encontra seu referencial, entre outros aspectos, no reduzido espa,co ocupado pelo tema "criança" namidia. Pesquisas realizadas pelo IBASERJ, durante o mês de abril/92, abordando os conteúdos dos noticiários de televisão, revelaram uma presença mínima e prejudicada pela abordagem carregada de preconceito. Em relação à saúde da criança, não houve uma citação sequer, ou seja, a questão da criança, e, especificamente as questões da saúde e desenvolvimento da criança, pouco ou nenhum espaço tem nos meios de comunicação de massa.

Mas qual o motivo para uma primeira opção pelo rádio? Em primeiro lugar porque o Brasil é um pais que ainda tem, sendo otirnista, 40 milhões de analfabctos, pessoas que não têm acesso aos códigos da linguagem escrita dos materiais impressos de informação e educação. O rádio, de alguma forma aponta como um espaço privilegiado para que se atinja essa grande margem de excluídos no país. Além desse argumento, existem outros; o rádio nas populações de baixa renda é o meio de maior expressão no cotidiano e possui uma grande credibilidade.

Os custos de produção e veiculação do rádio, diferentemente dos custos de produção da televisão e outros recursos audio-visuais, é acessível e contribui para a viabilidade de um projeto vinculado à comunicação popular.

Em consequência desses fatores, e de um forte apoio da UNDA, organização que congrega as emissoras de rádio católicas, partimos para o desenho de um programa de rádio, dentro do formato de rádio revista, denominado "Viva a Vida". Com duração de 15 minutos, destinado à veiculação semanal, este programa é produzido em duas versões: a primeira destinada aos públicos das regiões SUL, SUDESTE e CENTROOESTE, e outra destinada às regiões NORTE e NORDESTE.

Por que duas versões do programa Viva a Vida? Porque o Brasil é um pais dono de uma diversidade cultural muito grande. Temos do Norte ao Sul do pais várias culturas e realidades, seria muito difícil atender à signagemmultiforme fazendo um s6 programa. Num primeiro momento a solução se dá na criação de dois esquemas de produção, destinados ao complexo cultural NORTE/ NORDESTE, tendo como base uma certa unidade cultural, já que a ocupação do Norte foi feita por nordestinos que fugiram da seca e se transformaram na mão de obra do ciclo da borracha, daí surgindo forte identidade cultural. A mesma lógica se reproduz no SUL/CENTRO-OESTE, onde colonos oriundos da pressão económica sobre os minifúndios povoaram os estados do Mato Grosso, Goiás e Rondônia.

Nossa previsão, na época do lançamento do programa, julho de 1991, era de atingir 30 emissoras, entre as regiões Sul, Norte e Nordeste. Surpreendentemente, em dezembro do mesmo ano, já havíamos atingido 279 emissoras em todo o pais. Hoje ${ }^{2}$, o programa radiofónico Viva a Vida, está presente em 522 emissoras de rádio, sem contar as chamadas emissoras comunitárias. Diante de tal expansão, podemos considerar o programa como um sucesso editorial, principalmente diante do falo dele ser transmitido gratuitamente pelas emissoras de rádio.

A distribuição e controle de veiculação é feita diretamente pelas coordenações diocesanas ou paroquiais das cidades sedes das emissoras, cabendo ao nível central a responsabilidade pela produção, copiagem e envio das fitas às paróquias e dioceses.

Tendo como ponto de partida uma demanda espontânea de criação de versões regionais e locais do Viva a Vida, geralmente acoplados à versão produzida por nós, estamos iniciando um processo de capacitação de comunicadores populares em saúde, com concentração na produção radiofónica. O objetivo dessa iniciativa é, a médio e longo prazo, autonomizar os grupos populares e comunidades para que produzam seus próprios programas - é assim que entendemos a democratização do uso de meios de comunicação.

Paralelamente à realização das oficinas de rádio, estamos destinando parte do tempo dos encontros regionais e diocesanos à formação de grupos de leitura critica dos meios de comunicação de massa, assim como pensamos em expandir as oficinas de capacitação de comunicadores populares para a área de video, teatro e imprensa alternativa

Uma nova fase do trabalho com o rádio está se impondo. Épreciso estudar o papel do programa na fom^lação da imagem institucional, como apoio ao trabalho das lideres da Pastoral da

2 No momento da revisão do presente texto, novembro/92, 
Criança, como instrumento de informação na área de saúde da mulher e da criança, na mobilização e organização comunitária. Para isso, com o apoio da Universidade de São Paulo, o prof. Mauro Wilton de Souza, da Escola de Comunicação e Arte, desenvolveu um modelo de investigação de natureza qualitativa e quantitativa destinado à avaliação do Viva a Vida, previsto para iniciar as atividades de campo em março de 1993.

Um aspecto sobre o qual nós gostaríamos de chamar a atenção, relativo à estrutura do Viva a Vida é sua preocupação com o processo de formação da cidadania. Com esse objetivo alternamos temas específicos da criança, mulher e saúde, com temas gerais vinculados aos direitos sociais básicos da cidadania. A preocupação é estabelecer um vinculo permanente entre a dimensão macrosocial e a microsocial, onde os processos vitais ocorrem e onde se estabelecem as relações humanas.

Para encerrar este relato, gostaria de me reportar ao Relatório McBride, da UNESCO, na passagem onde diz o seguinte: Aloje em dia se considera que a comunicação é um dos aspectos dos direitos humanos, mas esse direito é cada vezmais concebido como o direito de comunicar, ultrapassando o direito de receber comunicação ou ser informado. Acredita-se que a comunicação seja um processo bidirecional, cujos participantes, individuais ou coletivos, mantém um diálogo democrático e equilibrado. Essa idéia de diálogo contraposta ao monólogo é a própria base de muitas idéias que levam ao reconhecimento de novos direitos humanos. $\mathrm{O}$ direito à comunicação constitui 0 prolongamento 16gico do progresso constante em direção à liberdade e à democracia. Todo mundo tem 0 direito de comunicar.”

O programa Viva a Vida deve sua existência ao apoio decisivo da CNBB, da Coordenaçào Nacional da Pastoral da Criança, das milhares de coordenadoras e lideres comunitárias e do apoio financeiro do FUNUAP e do UNICEF. 


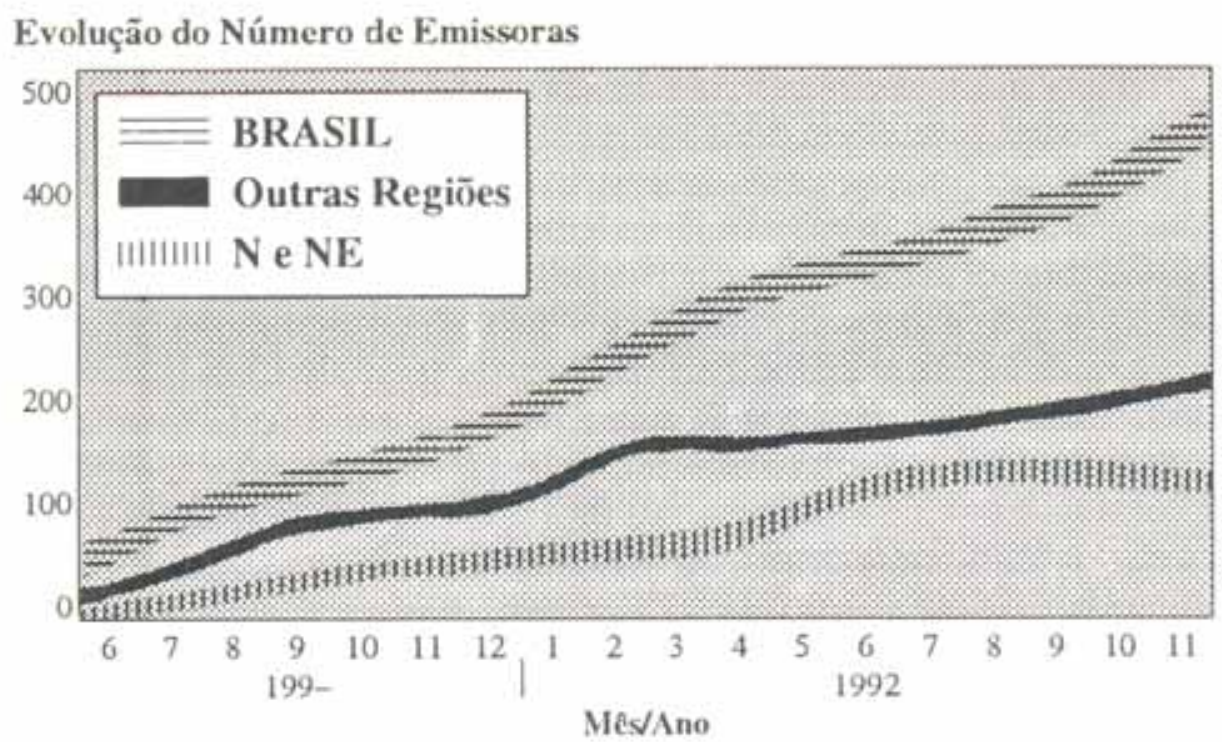

Forte: Cartas enviadas pelas Dioceses a Coondenaçäo Nacional da Pastoral da Criança att o día 03:11/92

\section{Número de Emissoras por Estado}

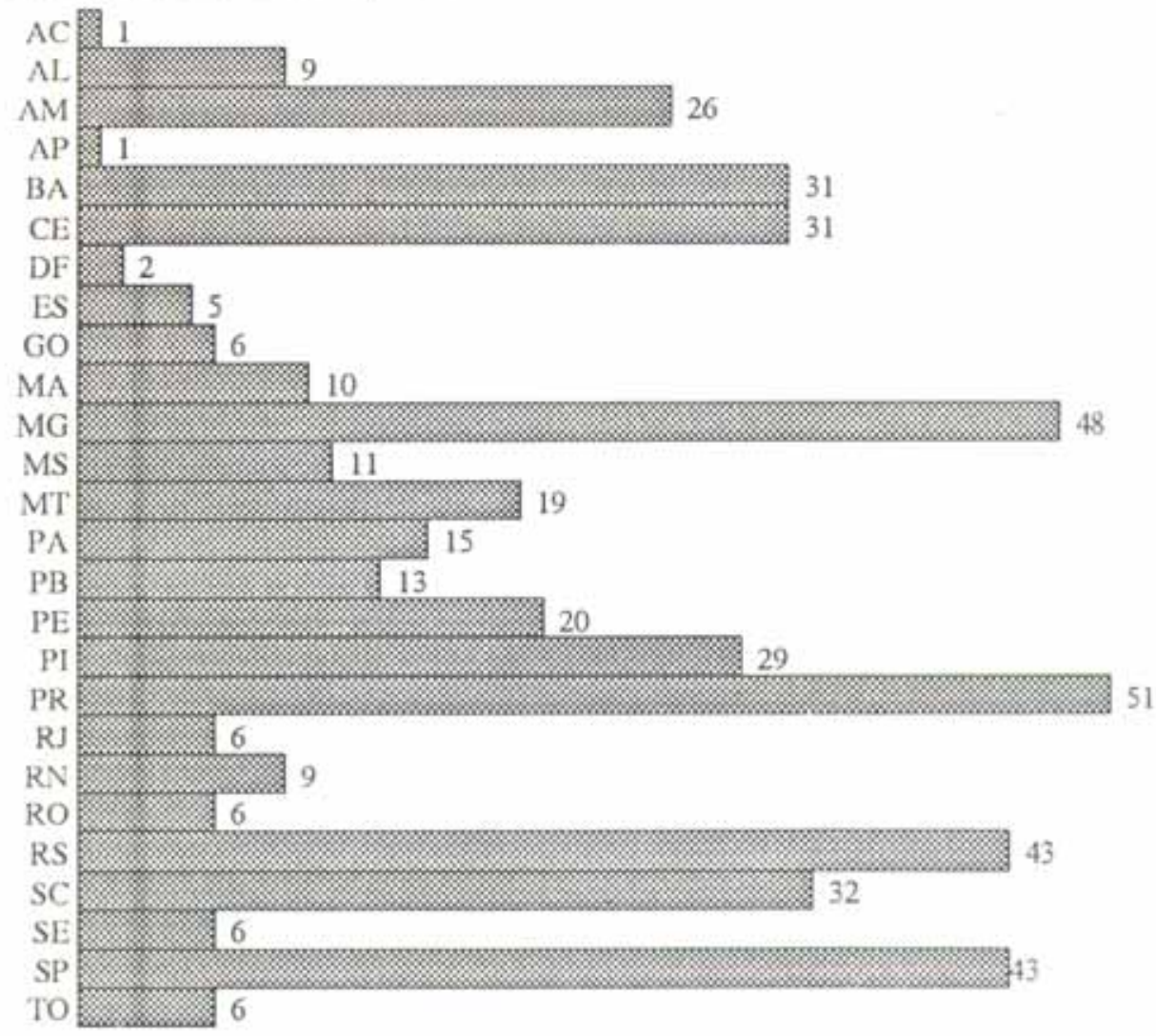

- O Programa de Radio Semanal "Viva a Vida" da Pastoral da Criança t produzido de forma regionalizada por (1) Pundaçầo D. Avelar Brandäo Vilela Radio Pionein de Tetesina-P1 para as regióes Nonte e Nordeste: (2) SIR-1_abo. ratirio de Som $\mathrm{t}$ Imagern-Curitiba PR para as regiórs Sul, Sudeste e Centro-Oeste. O Programa irn 15 minutos de duraça e veicula ternas educativos sobre saude, nutriçia, educaçio, patemidade tesponasavel e assuntos gefais de interesse para o desenvolvimento da populaçio de baika renda. 